\title{
Interplay between Lipid Interaction and Homo-coiling of Membrane- Tethered Coiled-Coil Peptides
}

\author{
Martin Rabe, ${ }^{* \dagger}$ Harshal R. Zope, ${ }^{\ddagger}$ and Alexander Kros* \\ Leiden Institute of Chemistry-Supramolecular and Biomaterial Chemistry, Leiden University, Einsteinweg 55, 2333CC Leiden, The \\ Netherlands
}

\section{Supporting Information}

\begin{abstract}
The designed coiled-coil-forming peptides E $\left[(\text { EIAALEK })_{3}\right]$ and $\mathrm{K}\left[(\mathrm{KIAALKE})_{3}\right]$ are known to trigger efficient membrane fusion when they are tethered to lipid vesicles in the form of lipopeptides. Knowledge of their secondary structure is a key element in understanding their role in membrane fusion. Special conditions can be found at the interface of the membrane, where the peptides are confined in close proximity to other peptide molecules as well as to the lipid interface. Consequently, different structural states were proposed for the peptides when tethered to this interface. Due to the multitude of possible states, determining the structure solely on the basis of circular dichroism (CD)
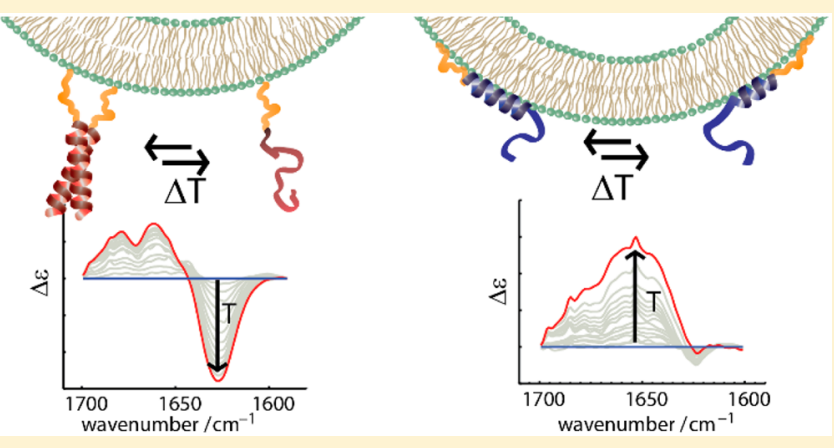
spectra at a single temperature can be misleading. In addition, it has not yet been possible to unambiguously distinguish between the membrane-bound and the coiled-coil states of these peptides by means of infrared (IR) spectroscopy due to their very similar amide $I^{\prime}$ bands. Here, the molecular basis of this similarity is investigated by means of site-specific ${ }^{13} \mathrm{C}$-labeled FTIR spectroscopy. Structural similarities between the membrane-interacting helix of $\mathrm{K}$ and the homo-coiled-coil-forming helix of $\mathrm{E}$ are shown to cause the similar spectroscopic properties. Furthermore, the peptide structure is investigated using temperaturedependent CD and IR spectroscopy, and it is shown that the different states can be distinguished on the basis of their thermal behavior. It is shown that the two peptides behave fundamentaly differently when tethered to the lipid membrane, which implies that their role during membrane fusion is different and the mechanism of this process is asymmetric.
\end{abstract}

\section{INTRODUCTION}

The hallmark of biological membrane fusion is the specific content mixing between two separate enclosed compartments without leakage. This makes this process an interesting target for supramolecular and biomaterials chemists as it opens a route to applications in biotechnology and drug delivery. Consequently, model systems have been designed with the aim of enabling membrane fusion by means of simple, synthetic molecules. ${ }^{1-3}$ Among those, membrane-tethered coiled-coilforming lipopeptides whose design has been inspired by natural SNARE (soluble NSF attachment protein receptor) proteins have been examined extensively in different studies because they were shown to trigger specific and leakage free full fusion of vesicles. ${ }^{1,4-15}$ The lipopeptides used here consist of a cholesterol lipid anchor connected via a polyethylene glycol $\left(\mathrm{PEG}_{12}\right)$ spacer to the peptide moieties (lipopeptides CPE, CPK; Chart $1 \mathrm{~A})$. The peptide recognition unit is made of two hetero-coiled-coil-forming peptides called E [(EIAALEK) $)_{3}$ $\left.\mathrm{NH}_{2}\right]$ and $\mathrm{K}$ [(KIAALKE $\left.)_{3}-\mathrm{NH}_{2}\right]$. Coiled-coils are peptide complexes consisting of several $\alpha$-helices that wind around each other. In their primary structure they show a specific arrangement of hydrophobic $(h)$ and polar $(p)$ amino acids in the so-called heptad repeat: hpphppp. The positions in this pattern are denoted abcdefg (Chart 1B). ${ }^{16}$
If two batches of vesicles bearing CPE and CPK on their membrane are mixed, these vesicles show full fusion. ${ }^{4,5,8}$ Although this capability has been extensively studied and the improvement of this system by means of synthetic variation of its components is an ongoing process, the detailed fusion mechanism and its common features with biological membrane fusion remain unclear. However, this knowledge is crucial for the rational improvement of these systems toward a targeted membrane fusion between artificial and biological membranes. $^{10}$

The initial docking step in this fusion process is triggered by the specific molecular recognition of the two hetero-coiled-coilforming peptides $\mathrm{E}$ and $\mathrm{K}$. The docking brings the two membranes into a close proximity. The peptide pair was designed rationally to form specific $\mathrm{E} / \mathrm{K}$ heterodimers. ${ }^{17}$ However, the membrane-tethered peptides can also have other interactions that were not intended in the initial lipopeptide design. Recent experimental and molecular dynamics (MD) studies showed that $\mathrm{K}$ interacts with lipid membranes, incorporating as an amphipathic $\alpha$ helix parallel to

Received: June 8, 2015

Revised: August 11, 2015

Published: August 24, 2015 
Chart 1. (A) Chemical Structures of CPK and CPE Lipopeptides Used in This Study, and Helical Wheel Projections ${ }^{16}$ of (B) E/K Coiled-Coil Complex and (C) Monomeric $\alpha$ Helices of K and E, Respectively ${ }^{a}$
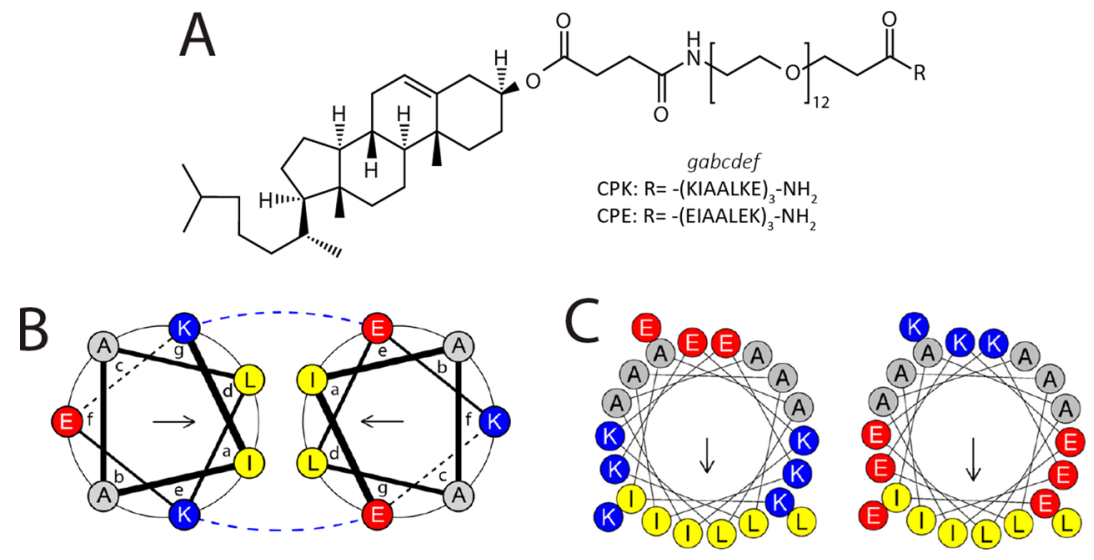

${ }^{a}$ Arrows indicate the direction of the hydrophobic moment.

the lipid interface. ${ }^{15,18,19}$ This interaction is anticipated to be a necessary requirement for subsequent steps in the fusion process as it provides the obligatory distortion of the membranes that enable full merging. ${ }^{15,20}$ Furthermore, both E and $\mathrm{K}$ tend to form homodimers in aqueous buffer. ${ }^{21}$ Both peptides have low folding constants for the homodimer formation relative to the heterodimer formation, but at high local concentrations, as found on the surface of vesicles, the peptides might tend to form homomeric aggregates. This means that, prior to the docking step, the membrane-tethered $\mathrm{E}$ and $\mathrm{K}$ can be in equilibrium between an unordered unbound state and different helical states: homo-coiled or membranebound.

In recent fusion studies, circular dichroism (CD) spectroscopy has been used to estimate the helical content of the peptides, because it is a quick and widely used technique that allows the direct study of vesicle-tethered lipopeptides as used in the fusion experiments. Generally, the vesicle-tethered lipopeptides exhibit increased helical contents compared to their untethered equivalents $\mathrm{E}$ and $\mathrm{K}$. This was always attributed to the formation of homo-coils $\mathrm{E} / \mathrm{E}$ and $\mathrm{K} / \mathrm{K}$, and peptide membrane interactions were not taken into account. $^{1,4-10}$ Typical CD spectra of $\alpha$-helices exhibit two minima around 208 and $222 \mathrm{~nm}$. Due to the low absolute ellipticity of other secondary structure elements at this position, the mean residual ellipticity at $222 \mathrm{~nm}\left([\theta]_{222 \mathrm{~nm}}\right)$ is a convenient measure for helical content. ${ }^{22,23}$ However, by using $[\theta]_{222 \mathrm{~nm}}$ only, it is not possible to distinguish whether the origin of this helicity is due to homomeric coiled-coil formation or the presence of single $\alpha$ helices. A second criterion which is commonly used for the characterization of coiled-coil complexes by $\mathrm{CD}$ is the ratio $[\theta]_{222 \mathrm{~nm}} /[\theta]_{208 \mathrm{~nm}} \cdot{ }^{17,24}$ However, $[\theta]_{208 \mathrm{~nm}}$ is often perturbed in experiments with vesicles, due to light scattering in this wavelength region. Also, the ratio $[\theta]_{222 \mathrm{~nm}} /[\theta]_{208 \mathrm{~nm}}$ might lead to inconclusive results in systems with coexisting unordered peptide chains. Therefore, CD data can be ambiguous in the case of complex systems and further analytical methods are required to obtain detailed information.

A potential way to obtain more information from CD data is to monitor thermally induced peptide unfolding. The melting curves can be analyzed to obtain information regarding the molecularity of peptide unfolding processes, ${ }^{21}$ and therefore pose a promising approach to distinguish coiled-coil formation from peptide membrane interaction.

An additional convenient method for the study of peptide and protein structures is Fourier transform infrared (FTIR) spectroscopy. The position of the amide I band, which mainly originates from the carbonyl stretching vibration of the peptide bond is known to strongly depend on its secondary structure. ${ }^{25}$ In $\mathrm{D}_{2} \mathrm{O}$ this band is usually referred to as amide $\mathrm{I}^{\prime}$. Coiled-coils have been shown to exhibit characteristic amide $\mathrm{I}^{\prime}$ bands with two main components, which are not observed for single helices. ${ }^{26-30}$ This pattern is caused by the different accessibility of the amide carbonyls for the solvent molecules. The carbonyls on the hydrophilic face, especially in the $b, c$, and $f$ positions of the heptad repeat can form additional hydrogen bonds with the solvent and absorb $\sim 20 \mathrm{~cm}^{-1}$ lower than the amides on the hydrophobic face. ${ }^{29,30}$ Surprisingly, a similar pattern was also found in amide $\mathrm{I}^{\prime}$ bands of peptide $\mathrm{K}$ interacting with model lipid monolayers using infrared reflection absorption spectroscopy (IRRAS) ${ }^{15}$ As an interaction of the peptide as a homomeric coiled-coil with the membrane seems unlikely, it was hypothesized that the pattern arises from a different accessibility of the carbonyls to water, caused by the shallow insertion of the single amphipathic $\alpha$-helix. This hypothesis allowed fitting of the angle dependency of the IRRA spectra, yielding the model of the helix insertion parallel to the membrane interface. Although a coherent bigger picture resulted from this approach, the origin of the two-band pattern in the lipid-bound form of $\mathrm{K}$ remains under investigation, due to lack of reports of comparable effects in literature. ${ }^{31-34}$ Therefore, further investigations of the IR spectroscopic properties of the membrane incorporated state of $\mathrm{K}$ together with an unequivocal band assignment are necessary to substantiate the helix insertion model. The latter can be done by site specific labeling of the amide with ${ }^{13} \mathrm{C}$, which is a convenient way to gain structural information for peptides at the residue level. ${ }^{29,35-41}$

In the present work we investigate the state of the vesicletethered lipopeptides under the conditions commonly used in the fusion studies. We extend the commonly used CD approach by monitoring melting curves of the coiled-coil-forming peptides E, $\mathrm{K}$ and their lipid-tethered equivalents CPE and CPK. This allows an unambiguous determination of the peptide state on the membrane. To verify the results of this approach, 
temperature-dependent IR spectroscopy is applied. A detailed analysis of these temperature dependencies by means of singular value decomposition (SVD) $)^{42-44}$ sheds light on the intrinsic temperature dependencies of the amide $\mathrm{I}^{\prime}$ two-band pattern and reveals structural properties of the peptides. Furthermore, the origin of the low-absorbing amide $\mathrm{I}^{\prime}$ component is determined by studying ${ }^{13} \mathrm{C}$-labeled peptide $\mathrm{K}$, which also reveals structural details of the membrane-bound state of K. Both applied techniques prove that, in these fusogenic vesicles, lipopeptides CPE and CPK are in different states, contrary to previous assumptions. The facile approach via $C D$ melting curves will be useful in future studies that vary the lipopeptide structure to enhance the fusogenity of the lipopeptides.

\section{RESULTS AND DISCUSSION}

CD of Free Peptides and Vesicle-Tethered Lipopeptides. Melting curves of peptides, monitored by CD spectroscopy, have been shown to contain relevant information about the molecularity of the peptide unfolding. ${ }^{21}$ The $\mathrm{CD}$ unfolding curves of untethered peptides $\mathrm{E}$ and $\mathrm{K}$ in the absence and presence of vesicles and tethered to the vesicle interface were measured (Figure 1). In these and all further experiments the
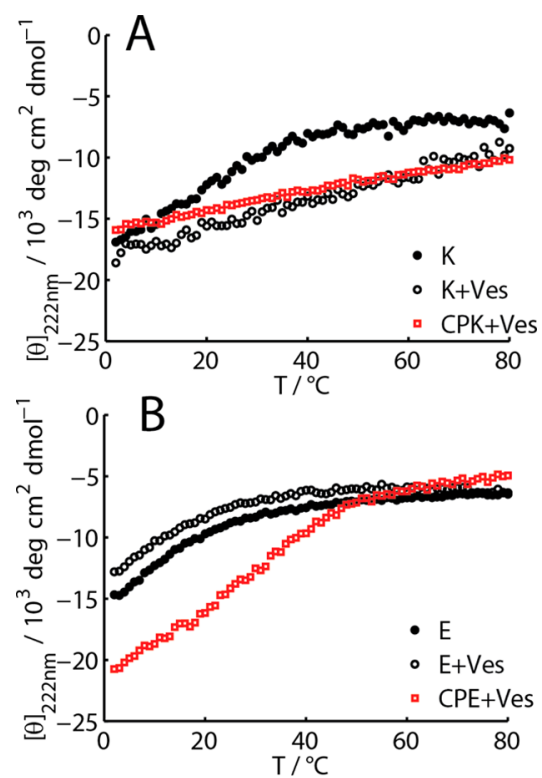

Figure 1. Temperature dependency of ellipticity at $222 \mathrm{~nm}$ for (A) K in buffer, $\mathrm{K}$ mixed with vesicles, and CPK tethered to vesicles, and for (B) $\mathrm{E}$ in buffer, $\mathrm{E}$ mixed with vesicles, and CPE tethered to vesicles. Experimental conditions: total peptide concentrations $[\mathrm{E}]=[\mathrm{K}]=40$ $\mu \mathrm{M} ;[\mathrm{CPE}]=[\mathrm{CPK}]=20 \mu \mathrm{M} ;[$ lipid $]:[$ peptide $]=[$ lipid $]$ : [lipopeptide] $=50: 1$. All measurements in PBS.

lipid composition was DOPC:DOPE:cholesterol (2:1:1), and the buffer was phosphate-buffered saline (PBS, $\mathrm{pH} 7.4$ ) as used in typical vesicle fusion experiments. ${ }^{1,4-10}$ Both free peptides exhibit shifts of the melting curves and the apparent melting temperature $T_{\mathrm{m}}$ toward higher temperatures with increasing peptide concentration (Supporting Information, Figure S1). ${ }^{2 \mathrm{~S}}$ In general, the $T_{\mathrm{m}}$ of a monomeric peptide chain is independent of concentration, while it is concentration dependent for olgomeric peptide complexes. ${ }^{45,46}$ Thus, the observed process is the unfolding of homomeric coiled-coils.
In a mixture with vesicles the $[\theta]_{222 \mathrm{~nm}}$ of $\mathrm{K}$ was significantly lower over the complete temperature regime; i.e., the helical content was increased (Figure 1A). This is caused by the interaction of the peptide with the lipid bilayer which is accompanied by its folding into an amphipathic helix. Compared to the experiment without vesicles, the shape of the curve appears almost linear with a shallower, uniform slope. In peptide folding studies, similar linear increases of folded coiled-coils are often considered as an intrinsic temperature induced change of the optical properties of the helix that does not relate to significant structural change. ${ }^{47}$ Another possibility is that it is caused by non-cooperative changes such as end fraying of helices. ${ }^{48}$ In contrast, $\mathrm{E}$ in a mixture with vesicles shows a very similar $[\theta]_{222 \mathrm{~nm}}$ curve to the lipid free solution (Figure 1B). The slight shift to higher values appears to be caused by light scattering by the vesicles. Thus, the untethered E shows no interactions with the vesicles that induce the formation of a helix.

The different membrane affininties of $\mathrm{E}$ and $\mathrm{K}$ probably arises from their different charge distribution (Chart 1C). ${ }^{15}$ This hypothesis is further enforced by recent MD simulations, where similar membrane affinity differences between $\mathrm{E}$ and $\mathrm{K}$ were observed. ${ }^{18,19}$ In principal both $\mathrm{E}$ and $\mathrm{K}$ would be able to form a monomeric amphipathic helix that enables them to interact with membrane interfaces. The main difference between the peptides lies in the distribution of the charged amino acids. In the helical wheel projection of $\mathrm{K}$ the positively charged lysine residues are distributed perpendicular to the hydrophobic moment, which is a so-called amphipathic $\alpha$ helix of class A according to the classification of Segrest et al. ${ }^{49}$ Peptides of this structure are commonly found in apolipoproteins and well known to interact with lipid membranes. For $\mathrm{E}$ the distribution is the opposite, a structure which has not been reported to interact strongly with membranes. For the amphipathic A helix it is thought that the relatively long lysine residues can "snorkel", i.e., bend toward the charged lipid headgroup region. This increases the hydrophobic face of the peptide, leads to a higher penetration depth of the peptide and hence to a stronger lipid binding. ${ }^{18,49-5}$

The membrane-tethered CPK also shows decreased $[\theta]_{222 \mathrm{~nm}}$ over the measured temperature range. It closely resembles $\mathrm{K}$ mixed with vesicles, indicating similarities in the structures and binding states of the peptides (Figure 1A). Based on $[\theta]_{222 \mathrm{~nm}}$ at $25{ }^{\circ} \mathrm{C}$, the helicity was found to be $45 \%$ and $48 \%$ for $\mathrm{K}$ and $\mathrm{CPK}$, respectively. Assuming that all peptides are membrane bound, this would imply that the peptides are only partially folded as a helix. However, from this data one cannot determine whether the observed helicity originates from a single state, populated by all peptide molecules or multiple states, differently populated.

$\mathrm{CPE}$, in contrast, shows a $[\theta]_{222 \mathrm{~nm}}$ curve that differs from its untethered equivalents (Figure 1B). A lower ellipticity was found, that increases up to $\sim 50{ }^{\circ} \mathrm{C}$ where the curve approaches those of the untethered peptides. This increase in helical content is generally attributed to the homo-coiling of the peptides. ${ }^{1,4-10}$ To scrutinize this, further experiments were performed by varying the lipopeptide concentration in the vesicles (Figure S3). CPK showed no significant changes in the temperature-dependent $[\theta]_{222 \mathrm{~nm}}$ with concentration change. In contrast, the $[\theta]_{222 \mathrm{~nm}}$ curves of CPE shifted slightly to lower temperatures with decreasing concentration. The derivatives do not consist of a single peak, indicating that the observed transition is not a simple two state unfolding. Consequently, 
fitting the data with several cooperative melting models with molecularities in the range $n=2, \ldots, 5$ yielded insufficient results (data not shown). The maxima in the first derivative also illustrate the shift of the apparent melting temperature $T_{\mathrm{m}}$ (Figure S3B, inset). Therefore, it shows that the unfolding of the peptide on the membrane is of a molecularity bigger than 1 , meaning it is a coiled-coil complex. . $^{21,45,46}$

The folded fraction $(\alpha)$ of peptide can be determined from the ellipticities at fully folded $\left(\theta_{\mathrm{F}}\right)$ and fully unfolded $\left(\theta_{\mathrm{U}}\right)$ states. Assuming values for a coiled-coil with high helical

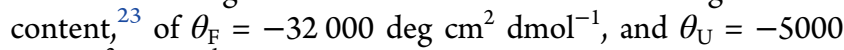
$\operatorname{deg} \mathrm{cm}^{2} \mathrm{dmol}^{-1}$ the value of $[\theta]_{222 \mathrm{~nm}}$ at $25{ }^{\circ} \mathrm{C}$ of $1 \mathrm{~mol} \% \mathrm{CPE}$ one can estimate that more than $37 \%$ of the CPE molecules are folded as homo-coils in a standard vesicle fusion experiment.

The melting of the untethered $\mathrm{E}$ and $\mathrm{K}$ showed that they are able to form homo-coils at relatively low folding constants, $K_{\mathrm{F}}$, compared to the $\mathrm{E} / \mathrm{K}$ hetero-coil (Supporting Information, Table S1). However, when tethered to the interface of the vesicles the local peptide concentration is drastically increased. This leads to a dramatically increased $T_{\mathrm{m}}$ of CPE compared to the untethered $\mathrm{E}$, despite the fact that the overall concentration is lower (Figure 1B). Using the experimental conditions of the melting curves in Figure 1B, this effect can be illustrated: the mean molecular density in a $40 \mu \mathrm{M}$ solution of untethered $\mathrm{E}$ is $\sim 24000$ molecules $/ \mu \mathrm{m}^{3}$, which is slightly less than the number of peptides that are confined to the lipid bilayer interface ( $\sim 33000$ molecules $/ \mu \mathrm{m}^{2}$ ) at $2 \%$ lipopeptide concentration and an average area of $60 \AA^{2}$ per lipid. It is clear that this corresponds to an immense agglomeration of molecules and thus to a high local concentration. This explains the substantial amount of homo coiling of CPE on the vesicles.

Similar experiments using vesicles with both lipopeptides present in the same sample did not yield reliable results, as membrane fusion occurred in these samples, which led to strong light scattering and sedimentation during $\mathrm{CD}$ and IR measurements (data not shown).

IR Spectroscopy of Peptides in Solutions. FTIR spectroscopy is a common technique to determine the secondary structure of peptides and proteins, because the position of the amide $\mathrm{I}^{\prime}$ band is strongly influenced by its secondary structure and hydrogen bond formation. Also, the melting processes that were followed by $\mathrm{CD}$ spectroscopy are expected to manifest in this band. ${ }^{40,44,52}$

First, the IR spectra of $\mathrm{E}, \mathrm{K}$, and $\mathrm{E} / \mathrm{K}$ in PBS prepared from $\mathrm{D}_{2} \mathrm{O}$ (d-PBS) were measured at $5{ }^{\circ} \mathrm{C}$. At a total peptide concentration of $1 \mathrm{mM}$ these peptides are expected to predominantly exist in the coiled-coil state at low temperatures. Accordingly, the amide $\mathrm{I}^{\prime}$ bands of the peptides are all dominated by two main components at $\sim 1630$ and $\sim 1649$ $\mathrm{cm}^{-1}$, which is a typical pattern for coiled-coils (Figure 2A). The origin of the additional small component at $1668 \mathrm{~cm}^{-1}$ is not clear but might be caused by residual trifluoroacetic acid (TFA) from the peptide purification, which is commonly found in this region. ${ }^{53}$ Additionally, at $1564 \mathrm{~cm}^{-1}$, the carbonyl stretching mode of the glutamic acid side chains can be found. $^{54}$

The positions of the underlying components in the amide $\mathrm{I}^{\prime}$ band were determined from the maxima in the smoothed second derivative. With this the shape of the bands could be adequately fitted with three Gaussians in these positions (Figure 2A, Table S2). The results of the band fitting procedures are detailed in the Supporting Information (Tables S2 and S3). Unless otherwise stated, all band fitting procedures
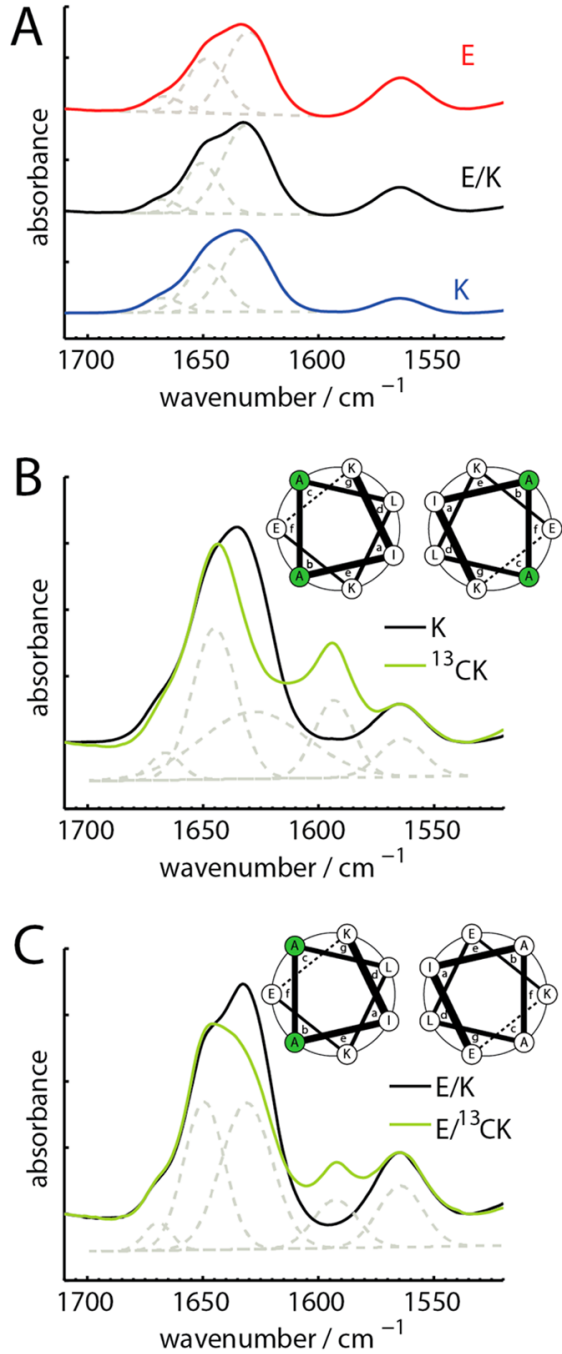

Figure 2. FTIR spectra (solid lines) and fits of the amide I' bands with gaussians (broken lines) of (A) $\mathrm{E}, \mathrm{E} / \mathrm{K}$, and $\mathrm{K}$ ([peptide] = $1 \mathrm{mM}$ ); (B) $\mathrm{K}$ and ${ }^{13} \mathrm{CK}$, and $(\mathrm{C}) \mathrm{E} / \mathrm{K}$ and $\mathrm{E} /{ }^{13} \mathrm{CK}$. $(\mathrm{B}, \mathrm{C})$ Only fitted amide $\mathrm{I}^{\prime}$ bands of ${ }^{13} \mathrm{C}$-labeled peptides are shown which are offset for clarity (broken lines). Spectra were normalized with respect to the $\mathrm{C}=\mathrm{O}$ stretching band of glutamic acid at $1565 \mathrm{~cm}^{-1}$. Insets show helical wheel projections of dimeric coiled-coils with the position of the ${ }^{13} \mathrm{C}$ labeled alanine residues highlighted in green. Experimental conditions for all spectra $(\mathrm{A})-(\mathrm{C}): T=5{ }^{\circ} \mathrm{C}$, [peptide] $=1 \mathrm{mM}$, in d-PBS.

yielded well separated peaks according to the $95 \%$ confidence intervals. The relative absorbance ratios of the two main components at 1630 and $1649 \mathrm{~cm}^{-1}\left(A_{1} / A_{2}\right)$ was determined. The lower $A_{1} / A_{2}$ ratio of $\mathrm{E}$ (1.75) and $\mathrm{K}(1.82)$ compared to $\mathrm{E} / \mathrm{K}$ (2.45) might arise from contributions of unordered structures. These are expected to overlap as a broad band centered at $\sim 1645 \mathrm{~cm}^{-1}$ (see below) and cannot be resolved in this manner. The addition of more than three bands will also result in an adequate description of the band shape and underlying hidden contributions cannot be excluded. For instance, Pähler et al. used five strongly overlapping bands to describe the amide $\mathrm{I}^{\prime}$ band of an $\mathrm{E} / \mathrm{K}$ variant tethered to a supported lipid bilayer. ${ }^{14}$ However, these bands appear overfitted and the authors state no rationale for this model. Since the simpler pattern with two main bands reported here can be explained with a consistent physical model, this interpretation is used. 
The two main components of the amide $\mathrm{I}^{\prime}$ band originate from the heterogeneous environment of the helix in the coiled coil. $^{26-30,33,55}$ The frequency of the amide $I^{\prime}$ band is known to shift down by $\sim 20 \mathrm{~cm}^{-1}$ per hydrogen bond to the amide carbonyl. The carbonyls on the hydrophobic face of the coiledcoil exclusively form intramolecular hydrogen bonds in the common $i$ to $i+4$ manner. On the other side, carbonyls on the hydrophilic face are available for one additional hydrogen bond from the solvent, which lowers their frequency.

To test this model, a variant of $\mathrm{K}$ was synthesized with the alanine residues situated in the $b$ and $c$ positions of the heptad repeat containing ${ }^{13} \mathrm{C}$-labeled carbonyls $\left({ }^{13} \mathrm{CK}\right)$. The isotope effect is known to specifically lower the amide $\mathrm{I}^{\prime}$ position of the labeled residue by $35-40 \mathrm{~cm}^{-1} \cdot{ }^{29,35-41}$ The IR spectra of ${ }^{13} \mathrm{CK}$ and $\mathrm{E} /{ }^{13} \mathrm{CK}$ at $5{ }^{\circ} \mathrm{C}$ showed strongly reduced intensities at $1630 \mathrm{~cm}^{-1}$ compared to their unlabeled equivalents (Figure 2B,C). Additionally a band at $\sim 1592 \mathrm{~cm}^{-1}$ arose, the amide I' band of the ${ }^{13} \mathrm{C}$-labeled carbonyls. The amide I' bands of ${ }^{13} \mathrm{CK}$ and $\mathrm{E} /{ }^{13} \mathrm{CK}$ could be fitted with 4 Gaussian bands. The carbonyl band of glutamic acid was included in the fit at 1564 $\mathrm{cm}^{-1}$, to enhance the band shape modeling at low frequencies. The fit of $\mathrm{E} /{ }^{13} \mathrm{CK}$ yielded $A_{1} / A_{2}=1.24$, which is smaller than the value for $\mathrm{E} / \mathrm{K}$ of 2.45 showing that the absorbance at 1630 $\mathrm{cm}^{-1}$ is significantly reduced (Table S2, Figure 2C). It is expected that some absorbance remains at $1630 \mathrm{~cm}^{-1}$ because the amide $\mathrm{I}^{\prime}$ bands of the amino acids in the $f$ position is expected at this wavenumber. ${ }^{29}$ The amide $\mathrm{I}^{\prime}$ band of the $e$ and $g$ positions have not been studied in detail yet. However, for ${ }^{13} \mathrm{CK}$, no specific, narrow band for the remaining ${ }^{12} \mathrm{C}$ carbonyls on the hydrophilic face at $\sim 1630 \mathrm{~cm}^{-1}$ could be resolved. Instead, band fitting yielded a relatively broad band at $\sim 1628$ $\mathrm{cm}^{-1}$, which might be the result of an overlap of the expected hydrogen-bound ${ }^{12} \mathrm{C}$ carbonyl and contributions from coexisting random structures. Nevertheless the reduction of the waterexposed helix band in this position is obvious (Figure 2B).

The reduced absorbance shows that the $1630 \mathrm{~cm}^{-1}$ component consists mainly of contributions from the alanine residues, which are situated on the hydrophilic face of the amphipathic helix in the $b$ and $c$ positions of the heptad repeat. This is further strengthened by the position of the ${ }^{13} \mathrm{C}$ amide $\mathrm{I}^{\prime}$ at $\sim 1592 \mathrm{~cm}^{-1}$ corresponding to an isotope shift of $\sim 38 \mathrm{~cm}^{-1}$, which is in range of the typical values of $35-40 \mathrm{~cm}^{-1}$ reported for different model peptides independent of their secondary structure and hydrogen-bonding state. ${ }^{29,35-41}$ Manas et al. reported the position of ${ }^{13} \mathrm{C}$-Ala in the $b$ and $f$ positions of a GCN4-p1' leucine zipper with $1587 \mathrm{~cm}^{-1}$ whereas a ${ }^{13} \mathrm{C}$-Leu in the $d$ position, i.e., the hydrophobic face of the same peptide absorbed at $1607 \mathrm{~cm}^{-1}$. 9 Thus, the position found in the present study reflects the expectation for a water-accessible helical ${ }^{13} \mathrm{C}$ amide $\mathrm{I}^{\prime}$ band.

IR of Lipopeptides. Next, the spectra of the lipopeptides $\mathrm{CPE}$ and CPK tethered to lipid vesicles were measured (Figure $3 \mathrm{~A})$. Just as for untethered $\mathrm{E}$ and $\mathrm{K}$, the amide $\mathrm{I}^{\prime}$ bands were dominated by two main components. Taking into consideration the strong absorbance of the lipid $\mathrm{C}=\mathrm{O}$ stretching band at $\sim 1740 \mathrm{~cm}^{-1}$, the amide $\mathrm{I}^{\prime}$ bands were fitted with Gaussians yielding $A_{1} / A_{2}$ values of 1.52 and 1.03 for CPE and CPK, respectively (Table $\mathrm{S3}$ ). For CPE this result is in line with the assumption that the peptide forms homo-coils on the vesicle interface. For CPK, this band shape is similar to amide $\mathrm{I}^{\prime}$ bands found in IRRA spectra from lipid monolayers containing the lipopeptide LPK with a DOPE anchor. ${ }^{15}$ Although the peptide moieties in these molecules are thought to interact as
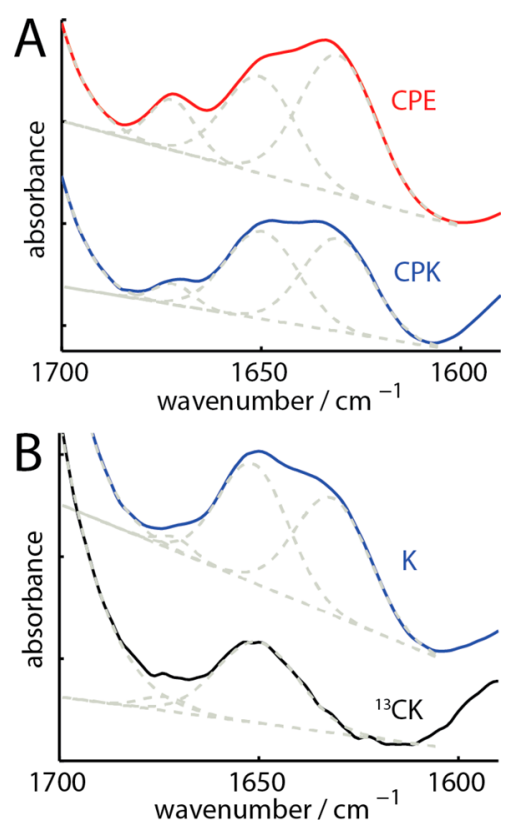

Figure 3. FTIR spectra (continuous lines) of vesicle-tethered (A) CPE and $\mathrm{CPK}_{\text {; }}$ (B) $\mathrm{K}$ at $5{ }^{\circ} \mathrm{C}$ and ${ }^{13} \mathrm{CK}$ at $10{ }^{\circ} \mathrm{C}$ mixed with vesicles at [lipid]:[peptide] $=200: 1$; [peptide] $=100 \mu \mathrm{M}$ and fits of the amide $\mathrm{I}^{\prime}$ bands with Gaussians (broken lines). All measurements in d-PBS.

monomers with the lipid bilayers, they show the typical amide $\mathrm{I}^{\prime}$ band shape of multimeric coiled-coils. However, $\mathrm{K}$ is thought to insert as an amphipathic A helix into one leaflet of the lipid bilayer with its helical axis parallel to the membrane interface. $^{15,18}$ This would also result in a shielding of the hydrophobic face from water. The water density in DOPC bilayers is known to drop significantly below the lipid phosphate group. ${ }^{56}$ This can explain the appearance of two amide $I^{\prime}$ components that can be attributed to solventaccessible and inaccessible carbonyls.

Although the assignment of water-accessible and buried amide $\mathrm{I}^{\prime}$ helical bands in coiled-coils is a well-studied phenomenon in solution, ${ }^{26-30,38,44,55,57,58}$ the related effect in a lipid membrane is reported only scarcely by other groups. A variable two-band pattern was reported by $\mathrm{Bi}$ et al. for an $S$ palmitoylated N-terminal peptide of pulmonary surfactant peptide SP-C interacting with DPPC monolayers. ${ }^{31}$ The authors interpreted a change of the relative band intensities with respect to each other as the expelling of helical fragments of the peptides from the monolayer, leading to a variation in hydration of the helix. Mukerjhee et al. found amide I' bands with solvent-accessible and buried components for alanine-rich helical peptides, and amphipathic helices in reverse micelles that mimic membrane water interfaces. 33,34

To verify the assignment of the two main bands to waterexposed and buried helices, the IR spectra of untethered $\mathrm{K}$ and ${ }^{13} \mathrm{CK}$ when interacting with vesicles were measured. Due to the need of a relatively high [lipid]:[peptide] ratio (200:1) the peptide concentration is relatively low in these experiments and the spectra are markedly affected by residual $\mathrm{H}_{2} \mathrm{O}$ below 1600 $\mathrm{cm}^{-1}$ and the strong lipid $\mathrm{C}=\mathrm{O}$ band above $1700 \mathrm{~cm}^{-1}$. While the influence of the lipid $\mathrm{C}=\mathrm{O}$ could be modeled by fitting additional large Gaussian bands, contributions below 1600 $\mathrm{cm}^{-1}$ could hardly be resolved. Despite that, the distinct twoband pattern described above can be found in the amide $\mathrm{I}^{\prime}$ band of $\mathrm{K}$ in the membrane, with $A_{1} / A_{2}$ being 1.05 , similar to CPK 

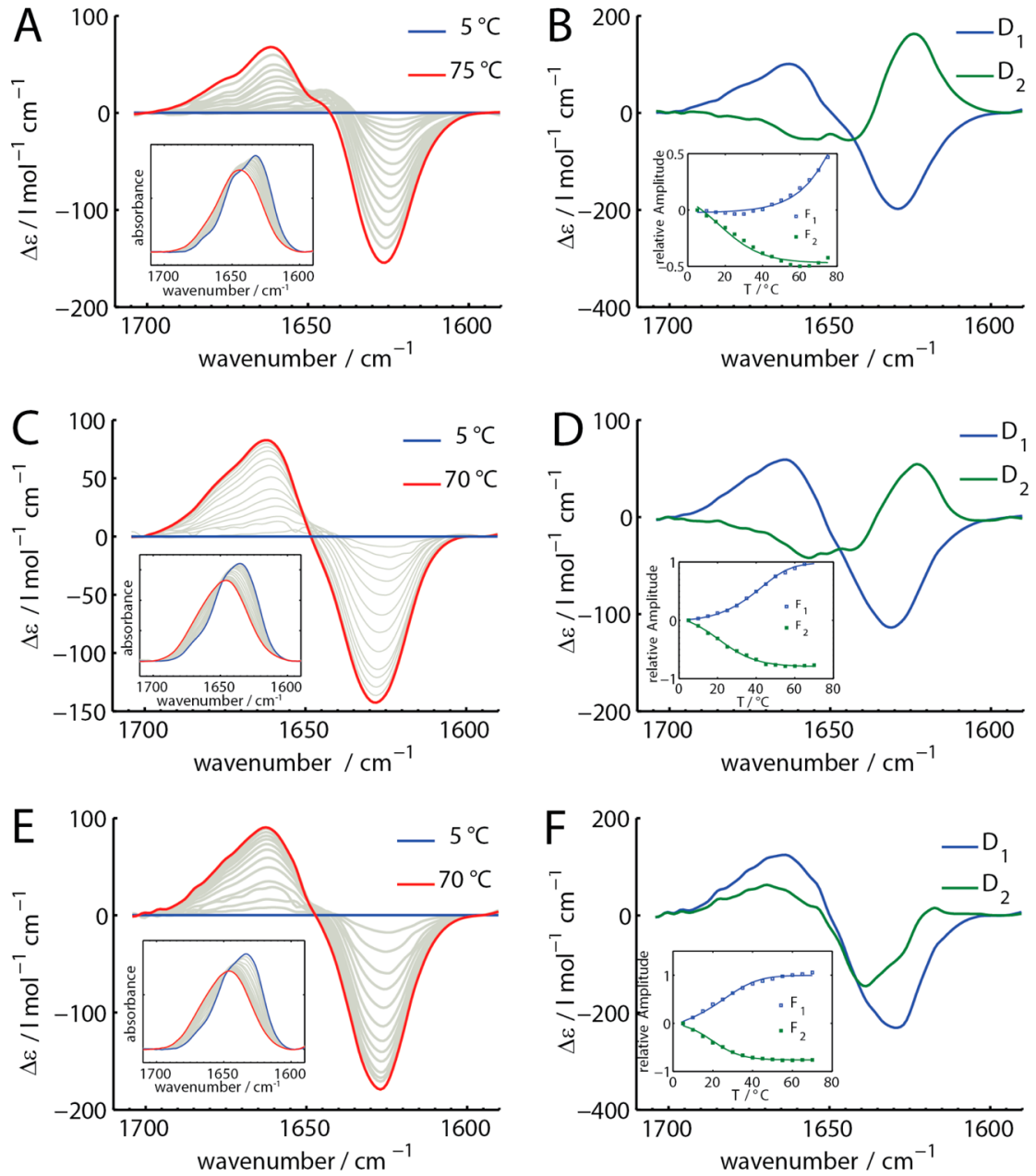

Figure 4. Temperature dependency and singular value decomposition of amide $\mathrm{I}^{\prime}$ bands for $(\mathrm{A}, \mathrm{B}) \mathrm{E} / \mathrm{K}, \mathrm{T}=5-75^{\circ} \mathrm{C}$; $(\mathrm{C}, \mathrm{D}) \mathrm{K}, \mathrm{T}=5-70{ }^{\circ} \mathrm{C}$; and $(\mathrm{E}, \mathrm{F}) \mathrm{E}, \mathrm{T}=5-70{ }^{\circ} \mathrm{C}$. (A,C,E) Temperature-dependent difference spectra in the amide $\mathrm{I}^{\prime}$ region with amide $\mathrm{I}^{\prime}$ bands in the insets in $5{ }^{\circ} \mathrm{C}$ steps. (B,D,F) Results of singular value decomposition $D_{1}$ and $D_{2}$ spectral components and $F_{1}, F_{2}$ temperature profiles (squares) and fit results (lines) in the insets; [peptide] = $1 \mathrm{mM}$, in d-PBS.

(Figure 3B, Table S3). Strikingly, the amide $\mathrm{I}^{\prime}$ band of ${ }^{13} \mathrm{CK}$ in the membrane showed a strongly reduced absorbance at 1630 $\mathrm{cm}^{-1}$ and no contribution at this position was necessary to fit the band shape. Remaining bands in this position could not be resolved due to the relatively low peptide signal. The reduced absorbance at $1630 \mathrm{~cm}^{-1}$ implies a high structural similarity of the membrane-bound and the homo-coiled state of $\mathrm{K}$. In both helices the alanine amide carbonyls are accessible for hydrogen bonds from water. A monomeric amphipathic A helix was proposed to be the membrane interacting species of $\mathrm{K}^{15,18}$ In this structure the alanine residues are also expected to be situated on the hydrophilic face, which is in common with their ${ }^{12} \mathrm{C}$ amide $\mathrm{I}^{\prime}$ absorbance at $\sim 1630 \mathrm{~cm}^{-1}$. The remaining peak, mainly centered at $1650 \mathrm{~cm}^{-1}$, is also in common with remaining absorbance of mostly buried ${ }^{12} \mathrm{C}$ amides of the hydrophobic face.

The relatively low $A_{1} / A_{2}$ ratios of $\mathrm{CPK}$ and $\mathrm{K}$ interacting with vesicles, compared to $\mathrm{CPE}$ or the homo coils of $\mathrm{E}, \mathrm{K}$ and $\mathrm{E} / \mathrm{K}$ might be caused by higher amounts of unordered structures (Tables S2 and S3). This correlates well with the helicity values found by $\mathrm{CD}$ spectroscopy. However, it is difficult to distinguish if unstructured contributions are caused by unfolded domains within individual chains with all peptides being membrane bound or by the existence of different peptide populations, i.e., helical and unstructured. Certain arguments speak for the former. An unstructured form would be expected to be in equilibrium with a homomeric coiled coil and would result in concentration-dependent temperature profiles. The absence of this concentration dependence (Figure S3A), might therefore be interpreted as the absence of different populations and supports the model of partially unfolded peptide chains. A partial unfolding is in common with recent results from Pluhackova et al. Using MD simulations the authors found that $\mathrm{K}$ loses up to $25 \%$ of its helicity when modeled with atomistic resolution in a lipid membrane environment. ${ }^{18}$ Also, short peptides tend to fray at their termini, ${ }^{41}$ and these ends might reach out of the membrane remaining unfolded. This means the slight positive slope of the temperature-dependent $[\theta]_{222 \mathrm{~nm}}$ might indicate an increasing non-cooperative end fraying, leading to a less folded state at higher temperatures. ${ }^{48}$

Temperature Dependencies of Peptides. The temperature-dependent unfolding of coiled-coils as measured by $\mathrm{CD}$ spectroscopy is also reflected in the temperature dependency of the amide $\mathrm{I}^{\prime}$ bands. Deconvolution of the amide $\mathrm{I}^{\prime}$ bands of the unfolded peptides $\mathrm{E}$ and $\mathrm{K}$ at $75^{\circ} \mathrm{C}$ yielded broad single bands centered at $\sim 1645 \mathrm{~cm}^{-1}$, with the TFA shoulder around $\sim 1668$ $\mathrm{cm}^{-1}$ (data not shown). Thus, the band of the unfolded peptides overlaps strongly with the two helical bands reported 

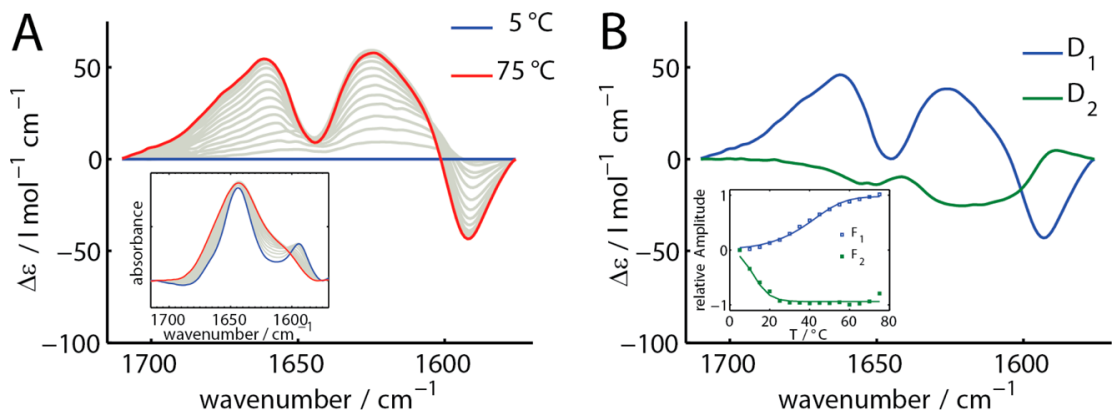

Figure 5. (A) Temperature-dependent difference spectra in the amide $\mathrm{I}^{\prime}$ region with amide $\mathrm{I}^{\prime}$ bands in the insets in $5{ }^{\circ} \mathrm{C}$ steps of ${ }^{13} \mathrm{CK}$ in d-PBS. (B) Results of singular value decomposition $D_{1}, D_{2}$ spectral components and $F_{1}, F_{2}$ temperature profiles (squares) and fit results (lines) in the insets, $T=$ $5-75^{\circ} \mathrm{C}$.
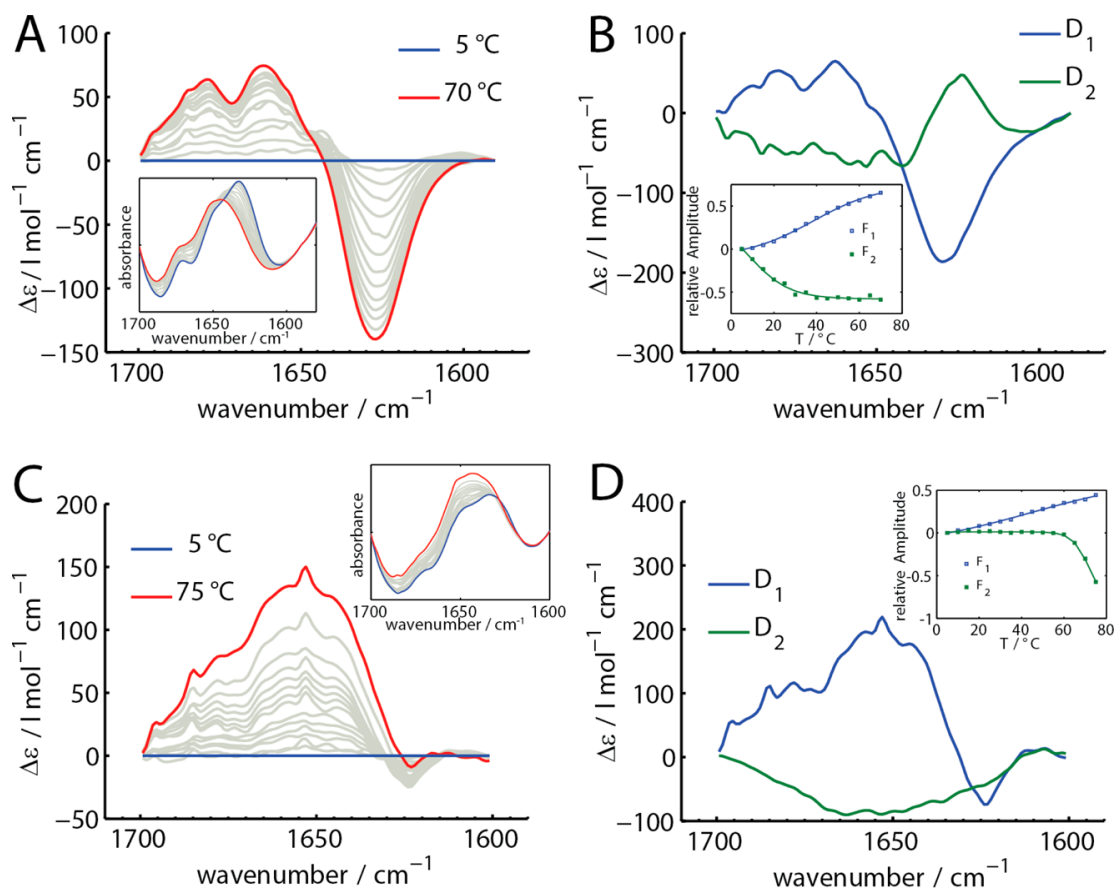

Figure 6. Temperature dependency and singular value decomposition of amide $\mathrm{I}^{\prime}$ bands for lipopeptides tethered to vesicles in d-PBS: (A,B) CPE, 1 mol\%, $T=5-70{ }^{\circ} \mathrm{C}$; (C,D) $\mathrm{CPK}, T=5-75^{\circ} \mathrm{C}$. (A,C) Temperature-dependent difference spectra in the amide $\mathrm{I}^{\prime}$ region with amide $\mathrm{I}^{\prime}$ bands in the insets in $5^{\circ} \mathrm{C}$ steps. (B,D) Results of singular value decomposition $D_{1}, D_{2}$ spectral components and $F_{1}, F_{2}$ temperature profiles (squares) and fit results (lines).

above. In order to clarify the changes in the amide I' band upon unfolding, difference spectra of the molar absorptivity per amino acid residue $\left(\Delta \varepsilon=\varepsilon_{\mathrm{T}}-\varepsilon_{5}{ }^{\circ} \mathrm{C}\right)$ are interpreted in the following (Figures 4-Figure 7). These are also sometimes referred to as "fingerprints" of a conformational change because they can be analyzed in terms of their magnitude, shape, and temperature dependence and classified according to their similarity. ${ }^{54}$

The straightforward interpretation of the difference spectra is hampered by the intrinsic temperature dependence of the amide $\mathrm{I}^{\prime}$ band components and artifacts from residual $\mathrm{H}_{2} \mathrm{O}$ in the case of low peptide signals (see below). For instance, the temperature-dependent difference amide $\mathrm{I}^{\prime}$ bands of $\mathrm{E} / \mathrm{K}$ clearly show no isosbestic point, which shows that more than one process affects the absorbance band (Figure 4A). The overlapping spectral changes can be separated by means of SVD in combination with a global fitting routine. ${ }^{42-44} \mathrm{~A}$ band can, for example, show an intensity decrease due to a reaction or a structural transition, at the same time this band can shift its position, due to changes in the strength of hydrogen bonds with temperature. These two spectral components overlap in the resulting difference spectra, both having their own temperature dependency. Under the assumption that the single spectral components have a temperature dependency of a sigmoidal shape, the different components that overlap in the spectrum can be distinguished using SVD. The results of this linear algebraic procedure are the separated spectral components $D_{1}, \ldots, D_{n}$ and their temperature dependencies $F_{1}, \ldots, F_{n}$ (Figure 4B,D,F) which, together, model the original temperature-dependent difference spectra. The resulting $D$ components can be interpreted to reveal molecular details of the temperature-dependent processes. The $F$ components yield the midpoints of the transitions $T_{\mathrm{m} 1}, \ldots, T_{\mathrm{m} 2}$ and their widths and describe the physics of the underlying process more precisely than measuring the absorbance at a single frequency. ${ }^{44}$

For the untethered peptides $\mathrm{E}, \mathrm{K}$, and $\mathrm{E} / \mathrm{K}$ one transition is assumed to be the unfolding of the coiled-coils, which is modeled in the $F_{1}$ component with the thermodynamic 

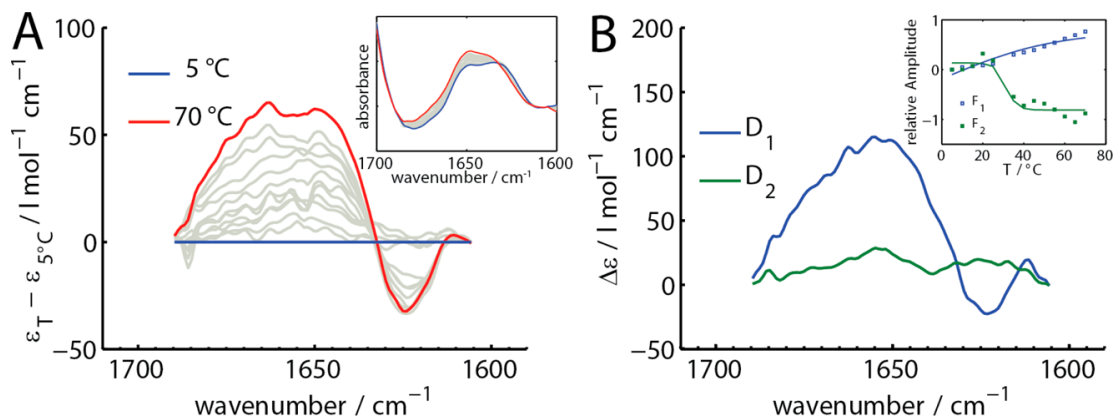

Figure 7. (A) Temperature-dependent difference spectra in the amide $\mathrm{I}^{\prime}$ region with amide $\mathrm{I}^{\prime}$ bands in the insets in $5{ }^{\circ} \mathrm{C}$ steps of $\mathrm{K}$ mixed with vesicles. (B) Results of singular value decomposition $D_{1}, D_{2}$ spectral components and $F_{1}, F_{2}$ temperature profiles (squares) and fit results (lines) in the insets $\left([\mathrm{K}]=100 \mu \mathrm{M}\right.$; [Lipid]:[K] $=200: 1$, in d-PBS), $T=5-70{ }^{\circ} \mathrm{C}$.

parameters $\left(\Delta H^{\circ}, \Delta c_{\mathrm{P}}, T^{\circ}\right)$ as determined from CD measurements (Table S1). The corresponding $D_{1}$ components of all peptides show a striking similarity with a strong and broad negative component centered at $\sim 1630 \mathrm{~cm}^{-1}$ and a positive feature at $1660 \mathrm{~cm}^{-1}$ (Figure 4B,D,F). The corresponding $F_{1}$ thermal components are all $\geq 0$, which means that the unfolding of the coiled-coils is always accompanied by a vanishing of the band at $1630 \mathrm{~cm}^{-1}$. In $\mathrm{K}$ and $\mathrm{E} / \mathrm{K}$ the $D_{2}$ components are very similar to a positive feature at $\sim 1624 \mathrm{~cm}^{-1}$ and negative intensity in the region $1640-1660 \mathrm{~cm}^{-1}$ (Figure 4B,D). Taking into account the negative values of $F_{2}$ over the whole temperature regime this corresponds to a blue shift of the water-exposed band of the coiled-coil spectrum. The midpoint of this transition $\left(T_{\mathrm{m} 2}\right)$ is below the melting temperature of the peptides which shows that the process influences the spectra less while the coiled coils melt. This blue shift is a known phenomenon for the water-exposed amide I' band of coiledcoils. Manas et al. reported that amide $\mathrm{I}^{\prime}$ bands of waterexposed carbonyls show stronger blue shifts at increasing temperature than buried ones, probably due to the weakening of the additional hydrogen bonds. ${ }^{29}$

The $D_{2}$ and $F_{2}$ components of E mainly overlap with its $D_{1}$ and $F_{1}$ components; i.e., in this case the SVD global fitting routine could not resolve additional information (Figure $4 \mathrm{~F}$ ). The low tendency of $\mathrm{E}$ to form homo-coils with the lower folding constant $K_{\mathrm{F}}$ at $25{ }^{\circ} \mathrm{C}$ (Table S1) leads to the presence of only a small amount of $\mathrm{E}$ homo-coils in the measured temperature range. Hence, there is only a small influence of the blue shift of the $1630 \mathrm{~cm}^{-1}$ band on the difference spectra.

While the water-accessible amide $\mathrm{I}^{\prime}$ band vanishes upon melting, the influence of melting on the solvent-buried amide $\mathrm{I}^{\prime}$ band is found in the difference spectra of ${ }^{13} \mathrm{CK}$ (Figure 5). The $D_{1}$ component indicates a broadening of the band at $\sim 1650$ $\mathrm{cm}^{-1}$, resulting from the rising of the band of unstructured peptide chains. The negative feature at $1590 \mathrm{~cm}^{-1}$ corresponds to the disappearance of the water-exposed ${ }^{13} \mathrm{C}$ amide $\mathrm{I}^{\prime}$ due to melting and is accordingly observed only in difference spectra ${ }^{13} \mathrm{CK}$ and $\mathrm{E} /{ }^{13} \mathrm{CK}$ (Figures 5 and $\mathrm{S} 4$ ). The temperaturedependent difference spectra of $\mathrm{E} /{ }^{13} \mathrm{CK}$ were found to be rather complex due to the multitude of bands. Thus, it is not discussed in detail; however, these spectra did not contradict the results described before (Figure S4).

Taken together the analysis of the temperature-dependent IR difference spectra of $\mathrm{E}, \mathrm{K},{ }^{13} \mathrm{CK}$, and $\mathrm{E} / \mathrm{K}$ revealed that the thermal unfolding of the coiled-coils can be retrieved by a specific difference spectrum. This "fingerprint" is dominated by a strong absorbance decrease at $1630 \mathrm{~cm}^{-1}$ and an increase at
$1650 \mathrm{~cm}^{-1}$. This overlaps with a more subtle shift of the wateraccessible helical band of the coiled-coil at $1630 \mathrm{~cm}^{-1}$ to higher frequencies, which occurs at temperatures below the cooperative melting temperature of the complex.

Strikingly, the thermal difference spectra of membranetethered CPE are also dominated by this pattern as can be seen in its $D_{1}$ component (Figure 6A,B). The $T_{\mathrm{m} 1}$ of the corresponding sigmoidal $F_{1}$ component is at $38{ }^{\circ} \mathrm{C}$, which lies well in the range of the $T_{\mathrm{m}}$ found in the $\mathrm{CD}$ unfolding curves (Figure S3). Furthermore, the $D_{2}$ component indicates a slight blue shift of the $1630 \mathrm{~cm}^{-1}$ band as was found for the untethered coiled-coils. This data therefore strongly suggest that membrane-tethered $\mathrm{E}$ is in a homomeric coiled-coil state, which unfolds upon heating (Figure 8A).

Conversely, the difference spectra of the membrane-tethered $\mathrm{CPK}$ and $\mathrm{K}$ mixed with vesicles show both $D_{1}$ components with a broad absorbance increase at $\sim 1650 \mathrm{~cm}^{-1}$ but only a small decrease at $1623 \mathrm{~cm}^{-1}$ (Figures 6C,D and 7). These spectral components differ substantially from the $D_{1}$ component of CPE and therefore indicate a different transition. The increase at $1650 \mathrm{~cm}^{-1}$ was also apparent in the $D_{1}$ component of ${ }^{13} \mathrm{CK}$ mixed with vesicles (Figure S5). The decrease at $1623 \mathrm{~cm}^{-1}$ appears to arise from the temperature-dependent blue shift of the water-exposed band. It has to be noted that the components found in the $D_{2}$ component of these measurements appear to be artifacts arising from variations in the residual $\mathrm{H}_{2} \mathrm{O}$ concentration in the sample. Band fitting of the spectra at $75{ }^{\circ} \mathrm{C}$ revealed that these amide $\mathrm{I}^{\prime}$ bands still consist of two main components of a similar area at 1635 and 1652 $\mathrm{cm}^{-1}$ (Figure S6). Interestingly, the corresponding $F_{1}$ components are relatively shallow and almost linear, indicating that the observed $D_{1}$ spectral component does not relate to a cooperative transition, which is in line with the almost linear shapes of the $[\theta]_{222 \mathrm{~nm}}$ curves of CPK and $\mathrm{K}$ mixed with vesicles (Figure 1).

This discussed data show that membrane-bound $\mathrm{K}$ exhibits a fundamentally different temperature dependency from an unfolding coiled-coil. Despite the expected blue shift of the water-accessible band, the amide $\mathrm{I}^{\prime}$ retains its two main components up to $75^{\circ} \mathrm{C}$. Thus, the peptide does not unfold cooperatively and stays bound to the membrane even at temperatures as high as $75{ }^{\circ} \mathrm{C}$ (Figure 8B). However, the intermediate helical content, decreasing with temperature found by $\mathrm{CD}$ (Figures 1 and $\mathrm{S} 3$ ) and the relatively low absorbance ratio $A_{1} / A_{2}$ (Table S3) indicate a certain contribution of unordered structure in the peptide chains which might, upon heating, increase in a non-cooperative way. 

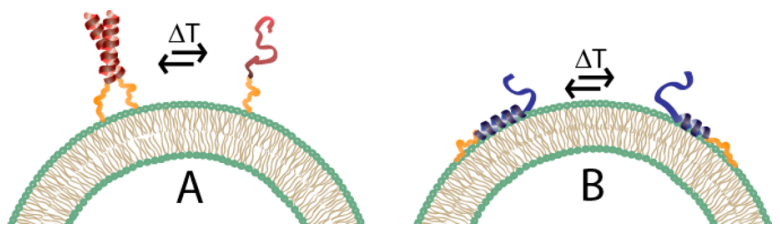

Figure 8. Schematic drawing of temperature-dependent changes of peptide states when tethered to membranes. (A) CPE is predominantly folded in an $\mathrm{E} / \mathrm{E}$ coiled coil which unfolds and dissociates upon heating. (B) CPK is predominantly bound to the membrane in a helical state and stays bound upon heating.

The prefusion states of the peptides at the membrane, have a direct impact on the fusion mechanism. As soon as CPE and CPK-bearing vesicles are mixed, they dock by formation of the hetero-coiled-coil and membrane fusion starts. The membraneinteracting form of $\mathrm{K}$ coexists with the $\mathrm{E} / \mathrm{K}$ hetero-coiled-coil during and after full fusion. ${ }^{15}$ As shown here, this membranepeptide interaction is of considerable strength, because it is stable up to $75{ }^{\circ} \mathrm{C}$, far above the melting of the $\mathrm{K}$ homo-coil. This interaction can deliver the membrane distortion and curvature that is necessary to complete full fusion. $\mathrm{K}$ has multiple functions within this mechansim in contrast to its binding partner $\mathrm{E}$, which makes it an asymmetric process. Furthermore, the $\mathrm{CD}$ and IR data presented here, show that the coexistence of $\mathrm{E}$ homo-coils with the $\mathrm{E} / \mathrm{K}$ hetero-coils during and after fusion is a further possibility. The prefusion states of both $\mathrm{E}$ and $\mathrm{K}$ might play a role when fusion goes over several rounds, as reported by Marsden et $\mathrm{al}^{4}$ It was stated that the coiled-coil peptides can be employed in repetitive dockingfusion cycles, implying that hetero-coiled-coils are able to dissociate. This is more favorable at the lipid interface than in solution, considering that the prefusion states are the products after dissociation at the membrane.

\section{CONCLUSIONS}

The temperature-dependent unfolding of the fusogenic coiledcoil-forming peptides $\mathrm{E}$ and $\mathrm{K}$ in solution and tethered to lipid vesicles could be followed by $C D$ and difference IR spectroscopy and yielded comparable temperature profiles. Membrane-tethered CPE showed concentration-dependent temperature profiles in $\mathrm{CD}$, typical of an unfolding transition and the IR spectral changes exhibit also the characteristics of coiled-coil unfolding. In contrast, CPK on membranes exhibits no transition, remaining in its membrane-bound state up to 75 ${ }^{\circ} \mathrm{C}$. The membrane-bound $\mathrm{CPK}$ also does not show high helicity, which indicate a partially folded helix in the membranebound state.

The IR spectra of membrane-tethered homo-coiled CPE and membrane incorporated, monomeric CPK show remarkable similarities, despite their different states. This is caused by similar accessibilities of the amide carbonyls for water in the coiled-coil and the amphipathic A helix which are both partially hydrophobically buried. These results contribute further to the model of lipopeptide mediated fusion as they show that it is an asymmetric process, meaning that the two complementary units behave fundamentally differently before, during, and after fusion. Furthermore, the results show, that the special conditions at the membrane interface have differing influences on the state of the membrane-tethered peptides, depending on their individual properties. This influence is difficult to predict and has to be studied for each peptide individually for future generations of the lipopeptides.
It was proposed earlier ${ }^{15}$ that the interaction of $\mathrm{K}$ with the membrane induces curvature which helps to overcome the highly curved intermediate states of lipid reorganization during fusion. Thus, a specific manipulation of the membrane affinity of $\mathrm{K}$ appears to be a promising handle to influence the fusion mechanism in future studies. For these future designs, the facile approach demonstrated here, using temperature- and concentration-dependent $\mathrm{CD}$ unfolding curves of vesicle-tethered lipopeptides will be helpful in determining the peptide state in the fusion experiments unambiguously.

\section{EXPERIMENTAL SECTION}

Materials. Fmoc-protected amino acids and Sieber amide resin for peptide synthesis were purchased from Novabiochem, and Fmocprotected $\left(1-{ }^{13} \mathrm{C}, 99 \%\right)$ L-alanine was purchased from Cambridge Isotope Laboratories. DOPC (1,2-dioleoyl-sn-glycero-3-phosphocholine), DOPE (1,2-dioleoyl-sn-glycero-3-phosphoethanolamine), and cholesterol were purchased from Avanti Polar Lipids. Solvents, buffer salts, $\mathrm{D}_{2} \mathrm{O}$, and $\mathrm{DCl}$ (deuterium content $\geq 99.9 \%$ ) were purchased from Sigma-Aldrich. All water was ultrapure with resistance $\geq 18 \mathrm{M} \Omega$ $\mathrm{cm}^{-1}$ and TOC $\leq 2 \mathrm{ppm}$ produced from a Milli-Q Reference A+ purification system. All experiments were carried out in phosphate buffered saline prepared in water (PBS) or $\mathrm{D}_{2} \mathrm{O}$ (d-PBS) of the composition $150 \mathrm{mM} \mathrm{NaCl}, 20 \mathrm{mM} \mathrm{PO}_{4}{ }^{3-}$ at $\mathrm{pH} / \mathrm{pD} 7.4 .^{59}$

Peptide Synthesis. The peptides E [Ac-(EIAALEK) ${ }_{3}-\mathrm{NH}_{2}$ ], K [Ac-(KIAALKE) $)_{3}-\mathrm{NH}_{2}$ ], and ${ }^{13} \mathrm{CK}$, with the same sequence as $\mathrm{K}$ and a ${ }^{13} \mathrm{C}$-amide-labeled alanine residue, were synthesized using standard Fmoc-chemistry on a Biotage Syro I and purified by RP-HPLC to yield a purity $>95 \%$ based on HPLC. Identity of the peptides was determined by LC-MS. The lipopeptides were synthesized and purified as described elsewhere. ${ }^{5,8}$ Peptides were solved in $10 \mathrm{mM}$ $\mathrm{HCl}$ and lyophilized three times to remove TFA. ${ }^{53}$ Peptide stock solutions in d-PBS were prepared at $\sim 2 \mathrm{mg} / \mathrm{mL}$ and diluted accordingly for the measurements. Lipopeptide stock solutions were prepared in a $\mathrm{CHCl}_{3}: \mathrm{MeOH}$; 3:1 solution and added to the lipids prior to solvent evaporation.

Vesicle Preparation. Lipid stock solutions of the composition DOPC:DOPE:Cholesterol (2:1:1) were prepared in $\mathrm{CHCl}_{3}: \mathrm{MeOH}$ 3:1. For experiments with lipopeptides, lipid stock solutions were mixed with CPK and CPE stock solutions to yield mixtures with the desired molar ratio. Lipid films were created by slow evaporation of the solvents under $\mathrm{N}_{2}$ stream and kept under vacuum overnight. The films were rehydrated with PBS or d-PBS yielding final lipid concentrations of typically $1-2 \mathrm{mM}$ for CD or $20 \mathrm{mM}$ for IR measurements. For measurements with untethered peptides, the lipid films were directly hydrated with solutions of the peptides. Large unilamellar vesicles (LUVs) were formed by sonication at $55{ }^{\circ} \mathrm{C}$ for $\sim 15 \mathrm{~min}$. The size of the vesicles was tested by DLS using a Malvern Zetasizer nano-s and was typically found to be $\sim 100 \mathrm{~nm}$.

Circular Dichroism Spectroscopy. CD measurements were performed on a Jasco J815 CD spectrometer equipped with a Jasco PTC 123 Peltier temperature controller. Samples were heated in $2 \mathrm{~mm}$ quartz cuvettes at a rate of $40{ }^{\circ} \mathrm{C} \mathrm{h}^{-1}$ in the range $2-95{ }^{\circ} \mathrm{C}$ and the elipticity at $222 \mathrm{~nm}\left(\theta_{222}\right)$ was measured as a criterion for $\alpha$-helicity. CD spectra between $190-260 \mathrm{~nm}$ were also collected at $T=5,25$, and $80{ }^{\circ} \mathrm{C}$. Spectra taken at $5{ }^{\circ} \mathrm{C}$ before and directly after a full heating cycle were found to be reproducible for all used samples. The mean residual ellipticity $[\theta]$ was calculated from the measured ellipticity $\theta$, the path length $l$, the molar monomer concentration $c_{\mathrm{M}}$, and the number of amino acids per peptide $N$ by

$$
[\theta]=\frac{\theta}{l c_{\mathrm{M}} N}
$$

The relative $\alpha$ helicity ( $\mathrm{rh}$ ) was calculated from $[\theta]_{222 \mathrm{~nm}}$, the mean residue ellipticity at $222 \mathrm{~nm}$, and $N$, the number of amino acids per peptide, by ${ }^{22,23}$ 


$$
\mathrm{rh}=\frac{[\theta]_{222 \mathrm{~nm}}}{-40 \times 10^{3} \mathrm{deg} \mathrm{cm}^{2} \mathrm{dmol}^{-1}\left(1-\frac{4.6}{N}\right)} \times 100 \%
$$

The fraction of folded peptide $\alpha$ is calculated, using the ellipticity when all molecules are folded or unfolded $\left(\theta_{\mathrm{F}}, \theta_{\mathrm{U}}\right)$, by

$$
\alpha=\frac{[\theta]-\theta_{\mathrm{U}}}{\theta_{\mathrm{F}}-\theta_{\mathrm{U}}}
$$

Concentration-dependent unfolding curves were used to determine the thermodynamics of folding of the free coiled coil complexes as detailed in the Supporting Information.

Transmission FT-IR Spectroscopy. Transmission FT-IR spectra were measured using a Bio-Rad Excalibur spectrometer equipped with a nitrogen-cooled MCT detector. A temperature-controlled liquid transmission cell with $\mathrm{CaF}_{2}$ windows and a fixed nominal path length of $50 \mu \mathrm{m}$ was used. The precise path length $(d)$ was determined by the interference fringe method. Sample spectra in d-PBS and reference spectra of d-PBS at $25{ }^{\circ} \mathrm{C}$ were measured at a resolution of $2 \mathrm{~cm}^{-1}$, with a zero-filling factor of 1 . Spectra were recorded between 5 and 75 ${ }^{\circ} \mathrm{C}$ in steps of $5{ }^{\circ} \mathrm{C}$. The temperature of the cell was measured and kept constant during measurement at $\pm 0.2{ }^{\circ} \mathrm{C}$. For each spectrum 128 scans were averaged. Several spectra were averaged and corrected by manual subtraction of a water vapor spectrum. The molar absorptivity per residue $(\varepsilon)$ was calculated from the absorbance $(A)$, the peptide concentration $(c)$, and the number of amino acid residues per peptide chain $(n)$ according to Beer-Lambert law:

$$
\varepsilon=\frac{A}{n c d}
$$

For band fitting ${ }^{60}$ of the amide $\mathrm{I}^{\prime}$ the second derivative of the spectra were smoothed for determination of the position of underlying bands. The positions found were used as input for fitting of the band shape with Gaussian peaks on a linear baseline by means of a trust-regionreflective algorithm.

Singular Value Decomposition and Global Fitting. For analysis of difference spectra from baseline corrected molar absorptivity spectra $\left(\varepsilon_{T}-\varepsilon_{5}{ }^{\circ} \mathrm{C}\right)$ SVD in combination with global curve fitting was applied. ${ }^{42-44}$ The data matrix $\mathbf{A}(\tilde{\nu}, T)$ was created by ordering the difference spectra in such a way that each column corresponds to a temperature. SVD is applied to the data matrix (MatLab function: $s v d$ ) yielding three matrices, $\mathbf{U}, \mathbf{S}$, and $\mathbf{V}^{\mathrm{T}}$ :

$$
\mathbf{A}(\tilde{\nu}, T)=\mathbf{U S V}^{\mathrm{T}}
$$

corresponding to the basis spectra $(\mathbf{U})$, the singular values $(\mathbf{S})$, and the transpose of the temperature development of the basis spectra $\left(\mathbf{V}^{\mathrm{T}}\right)$. From these matrices components above a rank $(r)$ of 2 were omitted as they mainly contained noise. To describe the data matrix on the basis of overlapping physical transitions, it is assumed that these matrices can be described by a matrix $\mathbf{D}$ containing the spectral components of the overlapping components and $\mathrm{F}^{\mathrm{T}}$ containing their temperature dependencies:

$$
\mathbf{U S V}^{\mathrm{T}}=\mathbf{D F}^{\mathrm{T}}
$$

Multiplication with the pseudo-inverse of $\mathbf{F}^{\mathrm{T}}\left(\mathbf{F}^{\mathrm{T}+}\right)$ yields

$$
\mathbf{D}=\mathbf{U S H}
$$

with

$$
\mathbf{H}=\mathbf{V}^{\mathrm{T}} \mathbf{F}^{\mathrm{T}+}
$$

This means the matrix $\mathbf{H}$ contains the coefficients determining how the weighted basis spectra (US) must be mixed to yield the spectral component matrix $\mathbf{D}$, and these coefficients can be obtained by globally fitting $\mathbf{V}^{\mathrm{T}}$ with physical models for each spectral component. The model used for measurements of lipopeptides or peptides with vesicles consisted of two sigmoid functions:

$$
\begin{aligned}
f(T)_{n}= & h_{n 1}\left(b_{1}+\frac{m_{1}-b_{1}}{1+\exp \left(\frac{T_{m_{1}}-T}{\delta_{1}}\right)}\right) \\
& +h_{n 2}\left(b_{2}+\frac{m_{2}-b_{2}}{1+\exp \left(\frac{T_{m_{2}}-T}{\delta_{2}}\right)}\right)
\end{aligned}
$$

In this equation, subscript $n$ refers to the $n$th row of the matrix $\mathbf{V}^{\mathrm{T}} ; h_{n 1}$ and $h_{n 2}$ are the corresponding elements of $\mathbf{H}$, while $b, m, T_{\mathrm{m}}$, and $\delta$ are the minimum value, maximum value, midpoint, and width of the two sigmoidal transitions. For fitting a trust-region-reflective algorithm (MatLab function: lsqcurvefit) was used, leaving the parameters $b, m$, $T_{\mathrm{m}}$, and $\delta$ global.

For melting of the coiled-coil peptides $\mathrm{E}, \mathrm{K}$, and $\mathrm{E} / \mathrm{K}$, one transition was assumed to be the thermal peptide unfolding. The parameters $\Delta H^{\circ}$ and $T^{\circ}$, the enthalpy and the temperature where the folding constant $K_{\mathrm{F}}=1$, and $\Delta C_{\mathrm{P}}$, the change in heat capacity upon folding, were determined by CD spectroscopy (see Supporting Information) and set constant during global fitting. In the applied model, the first sigmoid function was replaced by the temperature-dependent fraction of folded peptide $\alpha(T)$ :

$$
\begin{aligned}
f(T)_{n}= & h_{n 1}\left(\alpha(T)\left(m_{1}-b_{1}\right)+b_{1}\right) \\
& +h_{n 2}\left(b_{2}+\frac{m_{2}-b_{2}}{1+\exp \left(\frac{T_{m_{2}}-T}{\delta_{2}}\right)}\right)
\end{aligned}
$$

$\alpha(T)$ was calculated using the unfolded fraction $\beta(\beta=1-\alpha)$ from the analytical solutions of

$$
a \beta^{2}+\beta-1=0
$$

as described in detail elsewhere. ${ }^{21}$

The $\mathbf{F}$ matrix was determined from

$$
\mathbf{F}^{\mathrm{T}}=\mathbf{H}^{-1} \mathbf{V}^{\mathrm{T}}
$$

All calculations were performed using MatLab 2013a equipped with curve-fitting toolbox.

\section{ASSOCIATED CONTENT}

\section{S Supporting Information}

The Supporting Information is available free of charge on the ACS Publications website at DOI: 10.1021/acs.langmuir.5b02094.

Determination of peptide unfolding thermodynamics by $\mathrm{CD}$ spectroscopy as well as supporting tables and figures (PDF)

\section{AUTHOR INFORMATION}

\section{Corresponding Authors}

*E-mail (M.R.): m.rabe@mpie.de.

*E-mail (A.K.): a.kros@chem.leidenuniv.nl.

\section{Present Addresses}

$\dagger$ (M.R.) Department of Interface Chemistry and Surface Engineering, Max-Planck-Institute for Iron Research $\mathrm{GmbH}$, Max-Planck-Str. 1, 40237 Düsseldorf, Germany

$\ddagger$ (H.R.Z.) Laboratory of Nanomedicine and Biomaterials, Department of Anesthesiology, Brigham and Women's Hospital, Harvard Medical School, Boston, MA 02115, USA

Notes

The authors declare no competing financial interest. 


\section{ACKNOWLEDGMENTS}

We acknowledge Dr. A. L. Boyle for helpful advice and discussion on the manuscript. M.R. and A.K. acknowledge the support of the European Research Council via an ERC starting grant (contract 240391).

\section{REFERENCES}

(1) Marsden, H. R.; Tomatsu, I.; Kros, A. Model systems for membrane fusion. Chem. Soc. Rev. 2011, 40, 1572-1585.

(2) Ma, M. M.; Bong, D. Controlled Fusion of Synthetic Lipid Membrane Vesicles. Acc. Chem. Res. 2013, 46, 2988-2997.

(3) Kumar, P.; Guha, S.; Diederichsen, U. SNARE protein analogmediated membrane fusion. J. Pept. Sci. 2015, 21, 621-629.

(4) Robson Marsden, H.; Korobko, A. V.; Zheng, T.; Voskuhl, J.; Kros, A. Controlled liposome fusion mediated by SNARE protein mimics. Biomater. Sci. 2013, 1, 1046.

(5) Robson Marsden, H.; Elbers; Nina, A.; Bomans; Paul, H. H.; Sommerdijk; Nico, A. J. M.; Kros, A. A Reduced SNARE Model for Membrane Fusion. Angew. Chem., Int. Ed. 2009, 48, 2330-3.

(6) Tomatsu, I.; Marsden, H. R.; Rabe, M.; Versluis, F.; Zheng, T.; Zope, H.; Kros, A. Influence of pegylation on peptide-mediated liposome fusion. J. Mater. Chem. 2011, 21, 18927-18933.

(7) Versluis, F.; Dominguez, J.; Voskuhl, J.; Kros, A. Coiled-coil driven membrane fusion: zipper-like vs. non-zipper-like peptide orientation. Faraday Discuss. 2013, 166, 349-359.

(8) Versluis, F.; Voskuhl, J.; van Kolck, B.; Zope, H.; Bremmer, M.; Albregtse, T.; Kros, A. In Situ Modification of Plain Liposomes with Lipidated Coiled Coil Forming Peptides Induces Membrane Fusion. J. Am. Chem. Soc. 2013, 135, 8057-8062.

(9) Zheng, T. T.; Voskuhl, J.; Versluis, F.; Zope, H. R.; Tomatsu, I.; Marsden, H. R.; Kros, A. Controlling the rate of coiled coil driven membrane fusion. Chem. Commun. 2013, 49, 3649-3651.

(10) Zope, H. R.; Versluis, F.; Ordas, A.; Voskuhl, J.; Spaink, H. P.; Kros, A. In vitro and in vivo supramolecular modification of biomembranes using a lipidated coiled-coil motif. Angew. Chem., Int. Ed. 2013, 52, 14247-51.

(11) Voskuhl, J.; Wendeln, C.; Versluis, F.; Fritz, E. C.; Roling, O.; Zope, H.; Schulz, C.; Rinnen, S.; Arlinghaus, H. F.; Ravoo, B. J.; Kros, A. Immobilization of Liposomes and Vesicles on Patterned Surfaces by a Peptide Coiled-Coil Binding Motif. Angew. Chem., Int. Ed. 2012, 51, $12616-12620$

(12) Meyenberg, K.; Lygina, A. S.; van den Bogaart, G.; Jahn, R.; Diederichsen, U. SNARE derived peptide mimic inducing membrane fusion. Chem. Commun. 2011, 47, 9405-9407.

(13) Pähler, G.; Lorenz, B.; Janshoff, A. Impact of peptide clustering on unbinding forces in the context of fusion mimetics. Biochem. Biophys. Res. Commun. 2013, 430, 938-943.

(14) Pähler, G.; Panse, C.; Diederichsen, U.; Janshoff, A. Coiled-Coil Formation on Lipid Bilayers-Implications for Docking and Fusion Efficiency. Biophys. J. 2012, 103, 2295-2303.

(15) Rabe, M.; Schwieger, C.; Zope, H. R.; Versluis, F.; Kros, A. Membrane Interactions of Fusogenic Coiled-Coil Peptides: Implications for Lipopeptide Mediated Vesicle Fusion. Langmuir 2014, 30, 7724-35.

(16) Grigoryan, G.; Keating, A. E. Structural specificity in coiled-coil interactions. Curr. Opin. Struct. Biol. 2008, 18, 477-483.

(17) Litowski, J. R.; Hodges, R. S. Designing heterodimeric twostranded alpha-helical coiled-coils. Effects of hydrophobicity and alphahelical propensity on protein folding, stability, and specificity. J. Biol. Chem. 2002, 277, 37272-9.

(18) Pluhackova, K.; Wassenaar, T. A.; Kirsch, S.; Böckmann, R. A. Spontaneous Adsorption of Coiled-Coil Model Peptides K and E to a Mixed Lipid Bilayer. J. Phys. Chem. B 2015, 119, 4396-4408.

(19) Bulacu, M.; Sevink, G. J. A. Computational insight in the role of fusogenic lipopeptides at the onset of liposome fusion. Biochim. Biophys. Acta, Biomembr. 2015, 1848, 1716-1725.
(20) Chernomordik, L. V.; Kozlov, M. M. Protein-lipid interplay in fusion and fission of biological membranes. Annu. Rev. Biochem. 2003, $72,175-207$.

(21) Rabe, M.; Boyle, A.; Zope, H.; Versluis, F.; Kros, A. Determination of oligomeric states of peptide complexes using thermal unfolding curves. Biopolymers 2015, 104, 65-72.

(22) Chen, Y.-H.; Yang, J. T.; Chau, K. H. Determination of the helix and $\beta$ form of proteins in aqueous solution by circular dichroism. Biochemistry 1974, 13, 3350-3359.

(23) Gans, P. J.; Lyu, P. C.; Manning, M. C.; Woody, R. W.; Kallenbach, N. R. The helix-coil transition in heterogeneous peptides with specific side-chain interactions: Theory and comparison with CD spectral data. Biopolymers 1991, 31, 1605-1614.

(24) Cooper, T. M.; Woody, R. W. The Effect of Conformation on the Cd of Interacting Helices - a Theoretical-Study of Tropomyosin. Biopolymers 1990, 30, 657-676.

(25) Barth, A. Infrared spectroscopy of proteins. Biochim. Biophys. Acta, Bioenerg. 2007, 1767, 1073-1101.

(26) Heimburg, T.; Schuenemann, J.; Weber, K.; Geisler, N. Specific Recognition of Coiled Coils by Infrared Spectroscopy: Analysis of the Three Structural Domains of Type III Intermediate Filament Proteins. Biochemistry 1996, 35, 1375-1382.

(27) Reisdorf, W. C., Jr.; Krimm, S. Infrared amide I' band of the coiled coil. Biochemistry 1996, 35, 1383-6.

(28) Heimburg, T.; Schünemann, J.; Weber, K.; Geisler, N. FTIRSpectroscopy of Multistranded Coiled Coil Proteins. Biochemistry 1999, 38, 12727-12734.

(29) Manas, E. S.; Getahun, Z.; Wright, W. W.; DeGrado, W. F.; Vanderkooi, J. M. Infrared Spectra of Amide Groups in a-Helical Proteins: Evidence for Hydrogen Bonding between Helices and Water. J. Am. Chem. Soc. 2000, 122, 9883-9890.

(30) Walsh, S. T.; Cheng, R. P.; Wright, W. W.; Alonso, D. O.; Daggett, V.; Vanderkooi, J. M.; DeGrado, W. F. The hydration of amides in helices; a comprehensive picture from molecular dynamics, IR, and NMR. Protein Sci. 2003, 12, 520-31.

(31) Bi, X.; Flach, C. R.; Pérez-Gil, J.; Plasencia, I.; Andreu, D.; Oliveira, E.; Mendelsohn, R. Secondary Structure and Lipid Interactions of the N-Terminal Segment of Pulmonary Surfactant SP-C in Langmuir Films: IR Reflection-Absorption Spectroscopy and Surface Pressure Studies $\dagger$. Biochemistry 2002, 41, 8385-8395.

(32) Lewis, R. N. A. H.; Prenner, E. J.; Kondejewski, L. H.; Flach, C. R; Mendelsohn, R.; Hodges, R. S.; McElhaney, R. N. Fourier Transform Infrared Spectroscopic Studies of the Interaction of the Antimicrobial Peptide Gramicidin S with Lipid Micelles and with Lipid Monolayer and Bilayer Membranes. Biochemistry 1999, 38, 1519315203.

(33) Mukherjee, S.; Chowdhury, P.; Gai, F. Infrared Study of the Effect of Hydration on the Amide I Band and Aggregation Properties of Helical Peptides. J. Phys. Chem. B 2007, 111, 4596-4602.

(34) Mukherjee, S.; Chowdhury, P.; DeGrado, W. F.; Gai, F. Sitespecific hydration status of an amphipathic peptide in AOT reverse micelles. Langmuir 2007, 23, 11174-11179.

(35) Tadesse, L.; Nazarbaghi, R.; Walters, L. Isotopically enhanced infrared spectroscopy: a novel method for examining secondary structure at specific sites in conformationally heterogeneous peptides. J. Am. Chem. Soc. 1991, 113, 7036-7037.

(36) Decatur, S. M.; Antonic, J. Isotope-Edited Infrared Spectroscopy of Helical Peptides. J. Am. Chem. Soc. 1999, 121, 11914-11915.

(37) Barber-Armstrong, W.; Donaldson, T.; Wijesooriya, H.; Silva, R. A. G. D.; Decatur, S. M. Empirical Relationships between IsotopeEdited IR Spectra and Helix Geometry in Model Peptides. J. Am. Chem. Soc. 2004, 126, 2339-2345.

(38) Starzyk, A.; Barber-Armstrong, W.; Sridharan, M.; Decatur, S. M. Spectroscopic evidence for backbone desolvation of helical peptides by 2,2,2-trifluoroethanol: an isotope-edited FTIR study. Biochemistry 2005, 44, 369-76.

(39) Decatur, S. M. Elucidation of Residue-Level Structure and Dynamics of Polypeptides via Isotope-Edited Infrared Spectroscopy. Acc. Chem. Res. 2006, 39, 169-175. 
(40) Kubelka, G. S.; Kubelka, J. Site-Specific Thermodynamic Stability and Unfolding of a de Novo Designed Protein Structural Motif Mapped by 13C Isotopically Edited IR Spectroscopy. J. Am. Chem. Soc. 2014, 136, 6037-6048.

(41) Fesinmeyer, R. M.; Peterson, E. S.; Dyer, R. B.; Andersen, N. H. Studies of helix fraying and solvation using $13 \mathrm{C}^{\prime}$ isotopomers. Protein Sci. 2005, 14, 2324-2332.

(42) Hendler, R. W.; Shrager, R. I. Deconvolutions based on singular value decomposition and the pseudoinverse: a guide for beginners. $J$. Biochem. Biophys. Methods 1994, 28, 1-33.

(43) Henry, E. R.; Hofrichter, J. [8] Singular value decomposition: Application to analysis of experimental data. In Methods in Enzymology, Ludwig Brand, M. L. J., Ed.; Academic Press, 1992; Vol. Vol. 210, pp 129-192.

(44) Brewer, S. H.; Tang, Y.; Vu, D. M.; Gnanakaran, S.; Raleigh, D. P.; Dyer, R. B. Temperature dependence of water interactions with the amide carbonyls of alpha-helices. Biochemistry 2012, 51, 5293-9.

(45) Breslauer, K. J. [10] Extracting thermodynamic data from equilibrium melting curves for oligonucleotide order-disorder transitions. In Methods in Enzymology; Michael, L. Johnson, G. K. A., Ed.; Academic Press: New York, 1995; Vol. 259, pp 221-242.

(46) Doyle, C. M.; Rumfeldt, J. A.; Broom, H. R.; Broom, A.; Stathopulos, P. B.; Vassall, K. A.; Almey, J. J.; Meiering, E. M. Energetics of oligomeric protein folding and association. Arch. Biochem. Biophys. 2013, 531, 44-64.

(47) Greenfield, N. J. Using circular dichroism collected as a function of temperature to determine the thermodynamics of protein unfolding and binding interactions. Nat. Protoc. 2006, 1, 2527-35.

(48) Dragan, A. I.; Privalov, P. L. Unfolding of a Leucine zipper is not a Simple Two-state Transition. J. Mol. Biol. 2002, 321, 891-908.

(49) Segrest, J. P.; De Loof, H.; Dohlman, J. G.; Brouillette, C. G.; Anantharamaiah, G. M. Amphipathic helix motif: Classes and properties. Proteins: Struct., Funct., Genet. 1990, 8, 103-117.

(50) Mishra, V. K.; Palgunachari, M. N.; Segrest, J. P.; Anantharamaiah, G. M. Interactions of synthetic peptide analogs of the class A amphipathic helix with lipids. Evidence for the snorkel hypothesis. J. Biol. Chem. 1994, 269, 7185-91.

(51) Segrest, J. P.; Jones, M. K.; Mishra, V. K.; Anantharamaiah, G. $M$. Experimental and computational studies of the interactions of amphipathic peptides with lipid surfaces. In Current Topics in Membranes; Sidney, A., Simon, T. J. M., Eds.; Academic Press: New York, 2002; Vol. 52, pp 397-435.

(52) Kubelka, J. Multivariate Analysis of Spectral Data with Frequency Shifts: Application to Temperature Dependent Infrared Spectra of Peptides and Proteins. Anal. Chem. 2013, 85, 9588-9595.

(53) Andrushchenko, V. V.; Vogel, H. J.; Prenner, E. J. Optimization of the hydrochloric acid concentration used for trifluoroacetate removal from synthetic peptides. J. Pept. Sci. 2007, 13, 37-43.

(54) Barth, A.; Zscherp, C. What vibrations tell about proteins. Q. Rev. Biophys. 2002, 35, 369-430.

(55) Paschek, D.; Puhse, M.; Perez-Goicochea, A.; Gnanakaran, S.; Garcia, A. E.; Winter, R.; Geiger, A. The Solvent-Dependent Shift of the Amide I Band of a Fully Solvated Peptide as a Local Probe for the Solvent Composition in the Peptide/Solvent Interface. ChemPhysChem 2008, 9, 2742-2750.

(56) Kučerka, N.; Gallová, J.; Uhríková, D.; Balgavý, P.; Bulacu, M.; Marrink, S.-J.; Katsaras, J. Areas of Monounsaturated Diacylphosphatidylcholines. Biophys. J. 2009, 97, 1926-1932.

(57) Wang, T.; Lau, W. L.; DeGrado, W. F.; Gai, F. T-Jump Infrared Study of the Folding Mechanism of Coiled-Coil GCN4-p1. Biophys. J. 2005, 89, 4180-4187.

(58) Imamura, H.; Isogai, Y.; Takekiyo, T.; Kato, M. Effect of pressure on the secondary structure of coiled coil peptide GCN4-p1. Biochim. Biophys. Acta, Proteins Proteomics 2010, 1804, 193-198.

(59) Glasoe, P. K.; Long, F. A. Use of glass electrodes to measure acidities in deuterium oxide. J. Phys. Chem. 1960, 64, 188-190.

(60) Meier, R. J. On art and science in curve-fitting vibrational spectra. Vib. Spectrosc. 2005, 39, 266-269. 